\title{
El gemelo tonto (y dramaturgo) de Cervantes: últimas aportaciones a la bibliografía sobre el teatro cervantino
}

\author{
HÉctor URZÁIz TORTAJADA*
}

\begin{abstract}
Resumen
Artículo-reseña sobre algunas recientes novedades bibliográficas sobre el teatro cervantino: la edición de las Comedias y tragedias (dentro de la colección Biblioteca Clásica de la Real Academia Española) y el volumen Vida y escritura en el teatro de Cervantes (publicado por la Universidad de Valladolid en la serie Olmedo Clásico).
\end{abstract}

Palabras clave: Teatro; Cervantes; Edición crítica; Monografía.

Title: The fool twin (and dramatist) of Cervantes: last contributions to the bibliography of Cervantes' Theatre.

\begin{abstract}
Article-review on some recent publications about the Cervantes' Theatre: the edition of the Comedias y tragedias by the Real Academia Española (Biblioteca Clásica) and the monography Vida y escritura en el teatro de Cervantes (University of Valladolid-Olmedo Clásico).
\end{abstract}

Key words: Theatre; Cervantes; Edition; Monograph.

En la reciente edición académica de las Comedias y tragedias de Cervantes, señala Luis Gómez Canseco, su responsable general, que el autor del Quijote viene siendo objeto, como dramaturgo, «de un pimpampum crítico que insiste una y otra vez en la falta de unidad de acción del teatro cervantino, en la hete-

*Universidad de Valladolid.urzaiz@fyl.uva.es 
rogeneidad de unas escenas y materiales mal articulados entre sí, en el carácter episódico y ornamental de no pocas de sus secuencias o en el rígido inmovilismo de sus tramas». En su opinión (en líneas generales asumible), «más que de una carencia, hay que entender que se trata simplemente de un modo dramático propio, hijo del tiempo en que las comedias fueron concebidas $\rangle^{1}$. Esta cerrada defensa del teatro cervantino (más cervantinista tal vez que Cervantes) se remata con la provocativa afirmación de que «por más que escribiera para las tablas, Cervantes es siempre Cervantes, no el gemelo tonto de quien firmó el Quijote»» ${ }^{2}$.

No tenía razones Cervantes para la modestia, sin duda. Alguna vez hemos dicho (solo medio) en broma que Cervantes es, si no el mejor dramaturgo del Siglo de Oro, el autor de la mejor obra dramática de la época: el Quijote, libro teatral y esencialmente metateatral, nacido acaso como entremés burlesco y devenido después en novela (no falta quien, en cambio, intuye que su germen fue más bien un esbozo de novela ejemplar). Con el paso del tiempo, además, esa teatralidad del Quijote (en la que no vamos a insistir ahora) conllevó una progresiva quijotización del teatro ${ }^{3}$.

No parece difícil apreciar un fenómeno parecido en nuestros días, cuando -tanto al socaire de las conmemoraciones de 2005 como de las todavía vivas de 2015-2016- han proliferado acercamientos escénicos numerosos y variopintos a la figura de don Quijote. La última década ha dejado versiones teatrales de todo tipo (algunas no desdeñables, muchas vacuas y oportunistas), así como espectáculos inspirados en el Quijote que no pretenden adaptarlo para la escena sino aprovechar sus múltiples lecturas. Despuntan, en este sentido, los espectáculos cervantinos de la compañía Ron Lalá, una impecable muestra de cómo transitar con ingenio y buen gusto por las sendas menos trilladas ${ }^{4}$. Y hasta de sus Novelas ejemplares u otros inclasificables artefactos literarios cervantinos se está sacando jugo escénico en estos fastos; véanse las versiones teatrales del Viaje del Parnaso (a cargo de la Compañía Nacional de Teatro Clásico, en el «primer año Cervantes») o el doble montaje de El celoso extremeño y El licenciado Vidriera por Micomicón (en este segundo), por citar solo dos ejemplos curiosos.

Un balance positivo de la contribución teatral a las conmemoraciones de este «segundo año Cervantes» hacía también Francisco Rico en un medio de comunicación, tras repasar los últimos espectáculos de inspiración cervantina: «No ha sido el teatro quien [más] torpemente ha celebrado en España el cuarto centenario de nuestro máximo prosista. [Gracias a] las gentes de la farándula, pocas veces las subvenciones estarán mejor empleadas [...] La floración teatral del centenario podría satisfacer [a Cervantes] como premio de consolación» ${ }^{5}$.

1. Cervantes (2015: IX). Véase nuestra reseña de este libro en Castilla. Estudios de Literatura, 7 (2016).

2. Cervantes (2015: X).

3. Urzáiz (2007: 469-480).

4. Urzáiz (2015).

5. Rico (2016: 28). En el original: «No ha sido el teatro quien menos torpemente ha celebrado en España el cuarto centenario». 
Lo que apenas se hace, ni casi se ha hecho históricamente, es el teatro de Cervantes, sin que nadie sepa por qué. ¿Quizá porque no es bueno? ¿Por qué es tan de otra época, que ya era antiguo en la suya e inviable en la nuestra? Como se sabe, es una opinión algo extendida. Hay excepciones, claro, que casi siempre se salvan: a la cabeza, con una lógica unanimidad en el elogio, los entremeses en general (La Abadía, Els Comediants), El retablo de las maravillas en particular; ha habido unos Baños de Argel, adaptados por Nieva, todavía recordados; una Gran sultana de Marsillach que cosechó también cierto consenso en el aplauso; una Entretenida de Pimenta que algo menos; la Numancia, discutida y discutible, pero igualmente canónica por consenso y a la que siempre se vuelve (ahora desde el Teatro Español). No mucho más (aunque lo hay, no es objetivo de estas páginas repasar toda la puesta en escena moderna del teatro cervantino).

Hablábamos de la inmodestia de Cervantes respecto a su teatro, reconocida en las tan traídas y llevadas páginas preliminares de sus Ocho comedias: «En este prólogo salgo algún tanto de mi acostumbrada modestia», admitió en un punto. «Y aquí entra el salir yo de los límites de mi llaneza», añadió en otro (a confesión de parte...). Detalla también allí Cervantes algunos logros de sus primeras comedias: "La batalla naval, donde me atreví a reducir las comedias a tres jornadas, de cinco que tenían» (habrá que creerle, porque la comedia, como otras muchas suyas - «veinte o treinta»-, no se ha conservado); «fui el primero que representase las imaginaciones y los pensamientos escondidos del alma, sacando figuras morales al teatro, con general y gustoso aplauso de los oyentes», etcétera.

Como bien recordaba el propio Rico, veía Cervantes en el teatro «la senda más adecuada para ganar los dineros y la fama que tanto ambicionaba, pero también la eligió respondiendo a una auténtica vocación de dramaturgo». Sin embargo, tras la publicación del Quijote «quiso retomar ese camino, pero los gustos habían cambiado [...] ningún empresario estuvo dispuesto a montar sus obras $\iota^{6}$. Las amargas (y de nuevo inmodestas) palabras de Cervantes son palmarias en ese sentido; perdió el favor de público, autores e impresores:

Volví a componer algunas comedias, pero no hallé pájaros en los nidos de antaño; quiero decir que no hallé autor que me las pidiese, puesto que sabían que las tenía; y, así, las arrinconé en un cofre y las consagré y condené al perpetuo silencio. En esta sazón me dijo un librero que él me las comprara, si un autor de título no le hubiera dicho que de mi prosa se podía esperar mucho, pero que, del verso, nada [...] me dio pesadumbre el oírlo, y dije entre mí: «O yo me he mudado en otro o los tiempos se han mejorado mucho», sucediendo siempre al revés, pues siempre se alaban los pasados tiempos.

Torné a pasar los ojos por mis comedias y por algunos entremeses míos que con ellas estaban arrinconados, y vi no ser tan malas ni tan malos que no mereciesen salir de las tinieblas del ingenio de aquel autor a la luz de otros autores menos escrupulosos y más entendidos [...] pues yo no ofendo a nadie, y que advierta [aquel mi maledicente autor] que no tienen necedades patentes y descubiertas. 
Cumple aquí reseñar el nuevo cuarto a espadas que por Cervantes echa Luis Gómez Canseco, interpretando que, si bien el alcalaíno realiza en el pasaje anterior «una tácita crítica del teatro contemporáneo, que ya había plasmado en escritos precedentes», en realidad, más que «encomiar sus propias obras, las caracteriza como ajenas a las necedades dramáticas de otras comedias contemporáneas, que ya había censurado en la Primera parte del Quijote» ${ }^{7}$. En efecto, en el primer Quijote se hace una severa crítica del teatro contemporáneo ${ }^{8}$ :

$\mathrm{Y}$ todos estos inconvinientes cesarían, y aun otros muchos más que no digo, con que hubiese en la Corte una persona inteligente y discreta que examinase todas las comedias antes que se representasen (no sólo aquellas que se hiciesen en la Corte, sino todas las que se quisiesen representar en España), sin la cual aprobación, sello y firma ninguna justicia en su lugar dejase representar comedia alguna; y desta manera los comediantes tendrían cuidado de enviar las comedias a la Corte, y con seguridad podrían representallas, y aquellos que las componen mirarían con más cuidado y estudio lo que hacían, temerosos de haber de pasar sus obras por el riguroso examen de quien lo entiende; y desta manera se harían buenas comedias y se conseguiría felicísimamente lo que en ellas se pretende: así el entretenimiento del pueblo como la opinión de los ingenios de España, el interés y seguridad de los recitantes y el ahorro del cuidado de castigallos. (I, 48).

Como bien recuerda Gomez Canseco, en estos años, al mismo tiempo que «Lope comenzaba a asentar sus reales en el campo dramático», «se preparaba el terreno para unas controversias sobre la licitud del teatro» ${ }^{9}$. Y en el párrafo que acabamos de citar parece casi que Cervantes se postula para un inexistente puesto de censor mayor del Reino; recordemos que, casualidad o no, poco después llegaría una figura parecida, la del juez protector de las comedias, de la mano del Reglamento del Teatro promulgado en 1608.

Fue la de Cervantes, sin duda, una producción dramática importante en tanto en cuanto supuso un peldaño más en la evolución del teatro de su época hacia un arte dramático nuevo. Pero también arrastraba un lastre evidente (ciertas reminiscencias del estilo clásico: búsqueda de equilibrio, verosimilitud, respeto a las unidades dramáticas, profundización en los caracteres), topó con bastantes reticencias por parte de un público que se estaba acostumbrando a un teatro más asequible (argumentos sugerentes, protagonistas algo estereotipados, formas métricas populares) y no terminó de encontrar los cauces adecuados para transmitirlo, ni por la vía escénica ni por la vía impresa; y cuando acertó con la primera (de creerle, su comedia La confusa «pareció en los teatros admirable»), no lo consiguió con la segunda (esta comedia que, según él, «bien puede tener lugar señalado por buena entre las mejores», no se ha conservado ni impresa ni manuscrita).

7. Cervantes (2015: 14, n. 57 y 62).

8. En palabras de Gómez Canseco, «el canónigo de Toledo y el cura ponen de vuelta y media las comedias de este tiempo», en Cervantes (2015: volumen complementario, 9).

9. Cervantes (2015: volumen complementario, 12). 
La obsesión que denota Cervantes por su fracaso teatral es insoslayable, y la rivalidad literaria con Lope de Vega tiene ahí su origen, pese a lo cual siguió bastante de cerca (sobre todo en su segunda etapa) muchos de los principios del arte dramático del Fénix; la claudicación cervantina ante el éxito de la fórmula lopiana se quedó tal vez en tierra de nadie, sin llegar a producir una obra lograda ni trascendental pese a la aspiración de originalidad que la presidió.

$* * *$

Hasta aquí lo que más o menos ya sabíamos (aunque vemos que existe también una opinión bastante distinta, más benevolente). Vayamos ahora con algunas aportaciones nuevas. Acaba de presentarse en las Jornadas de Teatro Clásico de Olmedo la última entrega de la colección de libros sobre la comedia áurea «Olmedo Clásico», dirigida por Germán Vega García-Luengos y auspiciada por el Ayuntamiento de la Villa del Caballero y la Universidad de Valladolid. Se trata del volumen Vida y escritura en el teatro de Cervantes, edición al cuidado del propio Luis Gómez Canseco y María Heredia Mantis, donde se recogen los trabajos presentados en un coloquio celebrado en la Universidad de Huelva en octubre de 2015.

El grueso de las contribuciones de Vida y escritura en el teatro de Cervantes corresponde esencialmente (aunque no solo) al grupo de estudiosos que han editado las Comedias y tragedias cervantinas en el volumen académico que mencionábamos al comienzo de estas páginas. Es decir, cada editor cervantino del equipo capitaneado por Gómez Canseco ha reservado para estas páginas olmedanas algún aspecto pendiente de estudio de $s u$ comedia. El reparto de títulos tiene la siguiente correspondencia de nombres: El gallardo español (el propio Gómez Canseco), La casa de los celos y selvas de Ardenia (Sergio Fernández López), Los baños de Argel (Alfredo Baras Escolá), El rufián dichoso (Valentín Núñez Rivera), La gran sultana, doña Catalina de Oviedo (Gómez Canseco), El laberinto de amor (José Manuel Rico García), La entretenida (Ignacio García Aguilar), Pedro de Urdemalas (Adrián J. Sáez), El trato de Argel (María del Valle Ojeda Calvo), Tragedia de Numancia (de nuevo Baras Escolá) y La conquista de Jerusalén por Godofre de Bullón (Fausta Antonucci).

Pueden leerse en Vida y escritura en el teatro de Cervantes artículos que polemizan e inciden sobre aspectos muy concretos de varias de estas obras dramáticas cervantinas: Fausta Antonucci ofrece unas calas de crítica textual en La conquista de Jerusalén, a propósito de ciertas enmiendas ope ingenii de Stefano Arata y otros editores de esa obra. Sergio Fernández recorre $L a$ casa de los celos en busca de chistes, villancicos, versos y coplas, mientras que Florence d'Artois rastrea en esta misma comedia ecos paródicos ariostescos y antilopescos. Como antilopesca encuentra Marcella Trambaioli la figura de Pedro de Urdemalas, abordada tanto por Cervantes como por el Fénix de los Ingenios en un nuevo episodio de su guerra literaria, devenida en diálogo intertextual (que Adrián Saez amplía a otros autores y textos: Salas Barbadillo, Pérez de Montalbán, Diamante). Beatrice Pinzan nos acerca a una poética del silencio como recurso dramático en El laberinto de amor. 
Gómez Canseco hace acopio de plegarias, súplicas e invocaciones varias a las alturas (incluida la «oración laica» de la «buscadamente burlesca» comedia de La entretenida) en el conjunto del teatro cervantino: morfología, métrica, topoi. María Heredia Mantis analiza lo que llama las «palabras de soldado» (es decir, el léxico del mundo militar) en tres obras de Cervantes: Numancia, La conquista de Jerusalén y El gallardo español. Alfredo Baras, por su parte, propone una interpretación en clave histórico-política tanto de Los baños de Argel como de la Numancia, ya que encuentra alusiones a personajes y hechos reales ocultos tras ciertos elementos de ficción. Su tesis tiene algún componente de controversia (de hecho, el autor se defiende aquí de ciertos reproches sufridos a causa de cuestiones similares), por lo que nos detenemos un momento en ella.

Recordemos un pasaje de la Numancia en el que Escipión arenga a sus soldados y les recrimina su incapacidad para vencer la resistencia hispana, encontrando la causa principal en el trato frecuente con prostitutas:

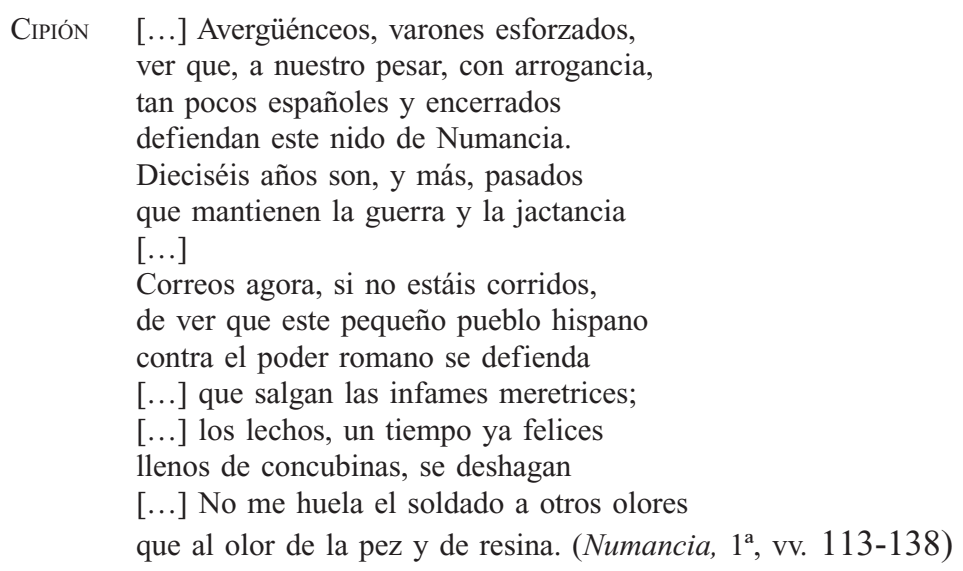

Pero fueron al parecer catorce, y no dieciséis, los años de resistencia numantina («así lo atestigua el propio Ambrosio de Morales e incluso siguen el tópico fray Antonio de Guevara, Lope de Vega, Medina o Mosquera»), supuesto error que Baras interpreta como una sutil crítica de Cervantes (quien no daba puntada sin hilo) en clave contemporánea:

¿Cómo pudo errar en punto tan crucial? Quizá la respuesta estribe en superponer a Numancia las guerras de Flandes [1567-1583]. Bajo el cerco de Numancia hemos de ver las reflexiones cervantinas sobre la única gran ciudad que pudo ser comparada, [Amberes] [...] En La Numancia late un fondo de crítica a Felipe II o a otras figuras de su reinado. (Vida y escritura, pp. 76-78 y 84)

Tiene también Baras la sospecha (igualmente controvertida) de que «cada uno de [los ocho Entremeses cervantinos] guarda estrecha relación con cada una de las comedias, según el orden en que iban a ser publicados en 1615», de donde se observarían «innumerables coincidencias en cada pareja». En virtud 
de esa tesis, para la que además ha de suponerse un error («basta con posponer las dos primeras comedias, como séptima y octava, o bien con adelantar los dos últimos entremeses, como primero y segundo»), quedarían emparejados Los baños de Argel con el entremés El juez de los divorcios (Vida y escritura, p. 79).

Hay en Vida y escritura en el teatro de Cervantes contribuciones a cargo de otros nombres, además de los citados editores del volumen de la Real Academia Española: Héctor Brioso Santos estudia la figura del mal poeta dramático en el entremés El retablo de las maravillas. Luigi Giuliani rastrea las huellas intertextuales del primer teatro cervantino (Argensola y, a través de él, Tasso). Y, por último, Antonio Rey Hazas reflexiona a propósito de la estructura y sentido de El trato de Argel (que no de La Numancia, como indica por error la presentación del volumen), particularmente sobre «el reproche histórico y político que la obra dirige, bien que indirectamente, contra Felipe II y su imperialismo anexionista portugués. Si don Juan de Austria viviera, parece decir la obra, habría más esperanzas» (Vida y escritura, pp. 69-70), comentario cercano en su tesis de fondo al de Alfredo Baras que acabamos de glosar.

El volumen Vida y escritura en el teatro de Cervantes, como decíamos, se ha presentado en julio de 2016 en el contexto de las XI Jornadas de Teatro Clásico de Olmedo, auspiciadas igualmente por Germán Vega desde la UVa y con un lema insistente en una conexión fundamental: Cervantes: el teatro o la vida. En el diálogo inaugural de estas jornadas, «Preguntar por Cervantes», el espíritu del escritor fue invocado por Javier Gomá (filólogo y filósofo) y por el historiador Alfredo Alvar, autor de la biografía cervantina Genio y libertad (2004), binomio estrechamente emparentado con el propio leitmotiv de estos encuentros como síntesis definitoria del homenajeado, puesto que la literatura y el teatro de Cervantes presentan cotas máximas de libertad creadora a lo largo de una andadura vital en la que el cautiverio - dentro y fuera de la patria, siempre ingrata con el escritor- pareciera ser el paradójico motor de su genio en rebeldía. Gomá y Alvar incidieron en esta idea de que «la literatura o la vida» de Cervantes son una disyuntiva indisoluble que unas veces asoma sin recato y otras se sugiere entre líneas o se deja inferir a lo largo y ancho de su legado literario, principio cervantino éste que nadie discute (o mejor dicho, nadie revoca) y que puede ser comprobado empíricamente en una exposición (anunciada por Alvar), que tendrá lugar en el Archivo de Simancas, en la que se exhiben más de doscientos documentos sobre el escritor y su familia ilustrados con pasajes literarios de su pluma. Gomá, por su parte, destacó en el genio y la figura de don Miguel tres dimensiones confluyentes: «el idealismo, el humor y la cortesía», lo cortés, que no le quita lo valiente al Cervantes que escribió a la muerte de Felipe II «fuese y no hubo nada», como recordó Alvar.

El Festival Olmedo Clásico, en el que se enmarcan estos diálogos, ha visto teatralizar novelas de Cervantes (Cervantes ejemplar, por Micomicón); y ha visto cervantear el teatro (el virus extendido por Ron Lalá y su Cervantina, sucediendo a su exitoso En un lugar del Quijote); pero no ha visto, en cambio, representar el teatro de Cervantes. Sobre eso precisamente, la ausencia del Cervantes dramaturgo en los escenarios actuales, han discutido 
en las jornadas olmedanas quienes bien pueden hacerlo: directores (Manuel Canseco, Helena Pimenta, Eduardo Vasco), críticos teatrales (Rosana Torres), cervantistas (José Montero) y hasta lopistas (Felipe Pedraza). Los abogados del demonio dramatúrgico cervantino se vieron reforzados esta vez desde la platea con la intervención de Esther Pérez Arribas, directora de la compañía Pie Izquierdo, que quiso arrojar una luz escénica sobreseída en la Numancia de la polémica recordando a quienes con mayor desahogo le detraían méritos (por achaque de antigualla antidramática) que el texto de la heroica resistencia ofrece lecturas de vergonzante actualidad a través de las mujeres numantinas (las mujeres libertarias de Lope o de Tirso sí gozan de reconocimiento), que dan voz a las madres de todo tiempo y lugar en asedio, en hambre, en miseria:

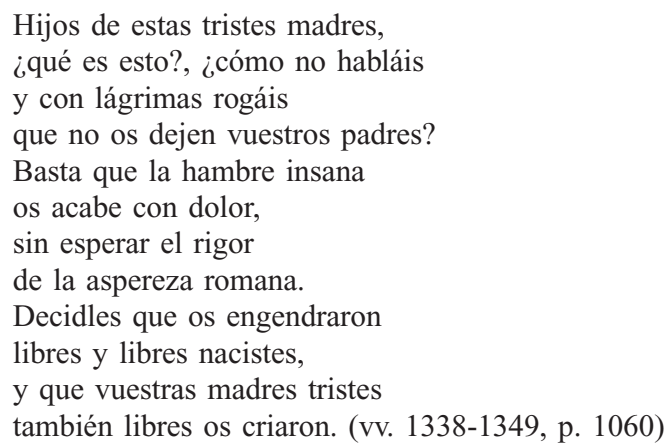

Las viejas polémicas, podemos dar fe, siguen sin resolverse; las querellas académicas, lejos de diluirse, se enquistan... Por suerte, cuando se da voz a sus textos por medio de actores excepcionales (Arturo Querejeta, Íñigo Echevarría, que de la mano de un inspiradísimo Emilio de Miguel recitaron inolvidables pasajes de Cervantes y Shakespeare, su partenaire conmemorativo de 2016), todo fluye de nuevo.

\section{BIBLIOGRAFÍA CITADA}

Cervantes, Miguel de (2015). Comedias y tragedias, Luis Gómez Canseco (ed.). Madrid: Biblioteca Clásica de la Real Academia Española.

Rico, Francisco (2016). «Bambalinas», en El País, 31 de mayo de 2016, p. 28.

Urzáiz, Héctor (2007). "La quijotización del teatro, la teatralidad de don Quijote", en Locos, figurones y quijotes en el teatro de los Siglos de Oro. Actas selectas del XII Congreso de la Asociación Internacional de Teatro Español y Novohispano de los Siglos de Oro (AITENSO). Ciudad Real: Universidad de Castilla-La Mancha, pp. 469-480.

Urzáiz, Héctor (2015). "En un lugar del verso: el Quijote de Ron Lalá", Don Galán. Revista de Investigación Teatral, 5, 2015 (teatro.es/contenidos/donGalan). 